\title{
Oscillator Strengths for the Helium Isoelectronic Sequence*
}

\author{
A. W. Weiss \\ Institute for Basic Standards, National Bureau of Standards, Waśhington, D.C. 20234
}

(October 16, 1966)

\begin{abstract}
Variational wavefunctions have been computed for the $1^{1} \mathrm{~S}, 2^{1,3} \mathrm{~S}, 2^{1,3} \mathrm{P}, 3^{1,3} \mathrm{P}$, and $3^{1,3} \mathrm{D}$ terms of ions in the helium isoelectronic sequence from $\mathrm{He}$ through $\mathrm{Ne}^{+8}$. The trial functions are Hylleraas type expansions, explicitly involving $r_{12}$, and with expansion lengths of around 50 terms, differing slightly for the different states. Oscillator strengths have been computed for all the allowed transitions by both the dipole length and velocity formulas. Agreement between these forms, comparisons with very accurate data for neutral helium, and the accuracy of the computed energies all point to considerable reliability of the results for the entire sequence, probably around 5 percent, if not better.
\end{abstract}

Key Words: Atomic term value, oscillator strengths, wavefunctions.

\section{Introduction}

While the spectra of neutral helium and singly ionized lithium have been studied quite thoroughly $[1,2],{ }^{1}$ the data available for the rest of this isoelectronic sequence leaves much to be desired. Be III, for instance, is the last ion for which the $2{ }^{1} \mathrm{~S}$ level has even been observed, and it is common for only a dozen or so levels to be known for any given ion [3]. The situation for oscillator strengths, of course, is no better, and with the exception of helium, where some accurate calculations have recently been made $[4,5]$, there is practically no reliable $f$-value data available. With the observational possibilities opened up by high energy plasma devices, accelerators, and astronomical spectroscopy in the ultraviolet, this gap in basic atomic data could assume considerable importance.

On the other hand, two-electron atomic systems are well-known for the relative ease with which one can make accurate variational calculations of wavefunctions and energies. The pioneering work of Hylleraas [6] showed that a linear expansion trial function with terms explicitly containing the interelectronic coordinate, $r_{12}$, would converge rapidly, and that the matrix elements could be given in a closed form amenable to numerical computation. Since then, helium, and to a lesser extent, the helium-like ions have been a favorite target for accurate variational calculations, primarily on the ground state. The most definitive calculations have recently been made by Pekeris and co-workers [7], who have also done extensive calculations on the helium excited states [8]; they have also

* Work supported in part by Project DEFENDER, sponsored by the Advanced Research Projects Agency, Department of Defense, through the Office of Naval Research.

${ }^{1}$ Figures in brackets indicate the literature references at the end of this paper. done some work on the $\mathrm{Li}^{+}$excited states [9]. Recently, also, configuration interaction expansions, which do not explicitly involve $r_{12}$, have yielded good results for the helium term values [10] and oscillator strengths [5].

In view of these observations, it seems clear that a systematic calculation of oscillator strengths for the isoelectronic sequence is not only desirable, but long overdue. With electronic computers, it is almost trivial to make calculations of relatively modest expansion lengths, which should still be sufficient to yield fairly definitive results. This paper reports the results of such calculations, employing of the order of 50 terms, for transitions among the $1^{1} \mathrm{~S}, 2^{1,3} \mathrm{~S}, 2^{1,3} \mathrm{P}$, $3^{1,3} \mathrm{P}$, and $3^{1,3} \mathrm{D}$ terms of the helium sequence through $\mathrm{Ne}^{+8}$.

\section{Description of the Calculations}

The Rayleigh-Ritz variational procedure is employed to calculate energies and wavefunctions, using the usual non-relativistic, spin-independent Hamiltonian, which in atomic units, ${ }^{2}$ is given by,

$$
\mathscr{H}=\frac{\Delta_{1}}{2}-\frac{\Delta_{2}}{2}-Z / r_{1}-Z / r_{2}+\frac{1}{r_{12}} .
$$

It is clear that all magnetic splittings and relativistic shifts are ignored, which can have a noticeable effect on the energy levels of the higher ions. The trial functions are taken to be linear expansions of the form,

$$
\psi=\sum_{n} c_{n} \Phi_{n}
$$

${ }^{2}$ In atomic units, $m_{e}=h=1$. The unit of length is the Bohr radius, $0.52917 \AA$, and the energy unit is $2 R_{M}$, where $R_{M}$ is the appropriate reduced mass Rydberg. 
The $c_{n}$ are linear variational parameters, and the twoelectron basis functions, $\Phi_{n}$, are of the usual Hylleraas variety,

$$
\begin{aligned}
\Phi_{p q \mu}=e^{-\rho_{1}-x \rho_{2} \rho_{l}^{l} \rho_{2}^{q} \rho_{12}^{\mu} Y_{l}^{m}\left(\theta_{2}, \varphi_{2}\right)} \\
\\
\pm e^{-\rho_{2}-x \rho_{1}} \rho_{2}^{p} \rho_{1}^{q} \rho_{12}^{\mu} Y_{l}^{m}\left(\theta_{1}, \varphi_{1}\right)
\end{aligned}
$$

with $\rho=\zeta r$,

and where $\zeta$ and $x$ are additional nonlinear parameters, $Y_{l}^{m}$ is the spherical harmonic appropriate for the desired angular momentum state, and the + and - signs refer to the singlet and triplet states, respectively. Since the spin functions factor out in the two-electron problem, all spin dependence has been suppressed.

Requiring the variation of the total energy,

$$
E=\frac{\langle\psi|\mathscr{H}| \psi\rangle}{\langle\psi \mid \psi\rangle}
$$

to be stationary with respect to variations of the coefficients leads to the matrix eigenvalue equation.

$$
\begin{gathered}
\sum_{j} H_{i j} C_{j}=E \sum_{j} S_{i j} C_{j} \\
H_{i j}=\left\langle\Phi_{i}|\mathscr{H}| \Phi_{j}\right\rangle, S_{i j}=\left\langle\Phi_{i} \mid \Phi_{j}\right\rangle .
\end{gathered}
$$

By selecting the $n$th eigenvalue, one has an upper bound to the energy of the corresponding excited state and, with appropriate nonlinear parameters in (3), an approximation to its wavefunction [11].

The oscillator strength for an electric dipole transition is given by

$$
f=\frac{2}{3} \frac{\Delta E_{i j}}{g_{i}}\left|\left\langle\psi_{i}|\mathbf{r}| \psi_{j}\right\rangle\right|^{2}
$$

where $i$ and $j$ refer to the initial and final states respectively, $\Delta E_{i j}$ is the energy difference in atomic units, and $g_{i}$ is the statistical weight of the initial state. It is further supposed that the squared matrix element has been summed over any degeneracies in either or both states. An alternative form is the dipole velocity form of the oscillator strength,

$$
f^{v}=\frac{2}{3} \frac{1}{g_{i} \Delta E_{i j}}\left|\left\langle\psi_{i}|\nabla| \psi_{j}\right\rangle\right|^{2}
$$

which should be identical in value with the dipole length form, although for approximate wavefunctions it may, and often does, disagree.

For sake of future reference, some of the other standard approximation schemes should probably be sketched here. The configuration interaction method follows the same general procedure outlined above, choosing the trial function to be a linear expansion as in (2). The two-electron basis, however, consists of products of one-electron functions (orbitals), of the general form

$$
\Phi_{p q}=\varphi_{p}(1) \varphi_{q}(2) \pm \varphi_{p}(2) \varphi_{q}(1)
$$

The Hartree-Fock model follows by choosing the trial function to be only the first term of a configuration interaction expansion with the orbitals occupied according to the aufbau principle, and adjusting the form of the orbitals to minimize the total energy.

\section{Results and Discussion}

The total energies computed for neutral helium are given in table 1 and compared with some other calculations. With the exception of the $4^{1,3} \mathrm{P}$ levels; all of the present calculations used expansion lengths of 52-54 terms. Positive powers of $r_{1}, r_{2}$, and $r_{12}$ through degree 5 were used, but with some selection, omitting some of the higher degree terms which made little difference in the total energy. For the $4 p$ levels, expansions of only 25 terms were used, because of difficulties encountered in getting the diagonalization to converge on the appropriate root for the longer expansions. It can be seen that, with the possible exception of the ground state, the configuration interaction calculation of Green et al. [5], is quite comparable to the ones reported here, and both compare quite well with the still more accurate calculations. The sole exception to this might be the $4 p$ levels calculated here, and for the reasons indicated above.

Tables 2 and 3 contain a similar comparison of oscillator strength calculations for neutral helium, including, in addition, the results of the Coulomb approximation of Bates and Damgaard [12]. The Hartree-Fock values reported here are not quite the same as in Trefftz et al. [13], due to the fact that the exact energy differences $\Delta \mathrm{E}$, were used in eqs (7) and (8). This was done throughout this paper, since it throws the burden of any discrepancies entirely on the calculated transition moment, which is the theoretically more critical quantity.

Probably the most obvious comment one can make about these results is that all the approximations dis-

TABLE 1. Computed total energies (in a.u.) for neutral helium

\begin{tabular}{l|c|c|c|c}
\hline \hline Term & $\begin{array}{c}\text { Hartree- } \\
\text { Fock }^{\mathrm{a}}\end{array}$ & $\begin{array}{c}\text { Configuration } \\
\text { interactior. }\end{array}$ & This paper & Accurate $^{\mathrm{c}}$ \\
\hline & & & & \\
$\mathrm{l}^{1} \mathrm{~S}$ & -2.86168 & -2.90338 & -2.90372 & -2.90372 \\
$2^{1} \mathrm{~S}$ & -2.14347 & -2.14594 & -2.14597 & -2.14597 \\
$3^{1} \mathrm{~S}$ & & -2.06126 & -2.06126 & -2.06127 \\
$2^{1} \mathrm{P}$ & -2.12246 & -2.12378 & -2.12384 & -2.12384 \\
$3^{1} \mathrm{P}$ & -2.05474 & -2.05513 & -2.05513 & -2.05515 \\
$4^{1} \mathrm{P}$ & -2.03090 & -2.03106 & -2.03095 & -2.03107 \\
$3^{1} \mathrm{D}$ & -2.05555 & -2.05561 & -2.05562 & $(-2.05562)$ \\
$2^{3} \mathrm{~S}$ & -2.17425 & -2.17521 & -2.17523 & -2.17523 \\
$3^{3} \mathrm{~S}$ & -2.06849 & -2.06868 & -2.06869 & -2.06869 \\
$2^{3} \mathrm{P}$ & -2.13143 & -2.13313 & -2.13316 & -2.13316 \\
$3^{3} \mathrm{P}$ & -2.05750 & -2.05807 & -2.05807 & -2.05808 \\
$4^{3} \mathrm{P}$ & -2.03213 & -2.03232 & -2.03220 & -2.03232 \\
$3^{3} \mathrm{D}$ & -2.05557 & -2.05563 & -2.05564 & $(-2.05564)$ \\
\hline
\end{tabular}

a See reference [13].

${ }^{\mathrm{b}}$ See reference [10].

' Except for the 3D terms, see references [8] and [9]. These terms were obtained from the observed levels-reference [2]. 
TABLE 2. Comparison of oscillator strength calculations for neutral heliumthe singlet transitions

\begin{tabular}{|c|c|c|c|c|c|c|c|}
\hline Transition & $\Delta E$ (a.u.) & Type & $\begin{array}{c}\text { Cou- } \\
\text { lomb } \\
\text { approx. }^{\mathrm{a}}\end{array}$ & $\begin{array}{c}\text { Hartree- } \\
\text { Fock }^{b}\end{array}$ & \begin{tabular}{|c} 
Config- \\
uration \\
inter- \\
action $^{c}$
\end{tabular} & $\begin{array}{l}\text { This } \\
\text { paper }\end{array}$ & $\begin{array}{l}\text { Accu- } \\
\text { rate }^{d}\end{array}$ \\
\hline $1^{1} \mathrm{~S} \rightarrow 2^{1} \mathrm{P}$ & 0.77988 & $\begin{array}{l}\text { len. } \\
\text { vel. }\end{array}$ & 0.259 & $\begin{array}{r}0.258 \\
.239\end{array}$ & $\begin{array}{r}0.2754 \\
.2759\end{array}$ & $\begin{array}{r}0.2759 \\
.2761\end{array}$ & $\begin{array}{r}0.2762 \\
.2762\end{array}$ \\
\hline $1^{1} \mathrm{~S} \rightarrow 3^{1} \mathrm{P}$ & .84858 & $\begin{array}{l}\text { len. } \\
\text { vel. }\end{array}$ & .0713 & $\begin{array}{l}.0707 \\
.0646\end{array}$ & $\begin{array}{l}.0729 \\
0730\end{array}$ & $\begin{array}{r}.0734 \\
.0730\end{array}$ & $\begin{array}{l}.0736 \\
.0734\end{array}$ \\
\hline $1^{1} \mathrm{~S} \rightarrow 4^{1} \mathrm{P}$ & .87265 & $\begin{array}{l}\text { len. } \\
\text { vel. }\end{array}$ & .0312 & $\begin{array}{l}.0312 \\
.0266\end{array}$ & $\begin{array}{l}.0296 \\
.0296\end{array}$ & $\begin{array}{l}.0302 \\
.0303\end{array}$ & \\
\hline $2^{1} \mathrm{~S} \rightarrow 2^{1} \mathrm{P}$ & 0.02213 & $\begin{array}{l}\text { len. } \\
\text { vel. }\end{array}$ & 0.390 & $\begin{array}{r}0.390 \\
.340\end{array}$ & $\begin{array}{r}0.3773 \\
.3950\end{array}$ & $\begin{array}{r}0.3764 \\
.3774\end{array}$ & $\begin{array}{r}0.3764 \\
.3764\end{array}$ \\
\hline $2^{1} \mathrm{~S} \rightarrow 3^{1} \mathrm{P}$ & .09083 & $\begin{array}{l}\text { len. } \\
\text { vel. }\end{array}$ & . 160 & $\begin{array}{l}.160 \\
.154\end{array}$ & $\begin{array}{l}.1513 \\
.1540\end{array}$ & $\begin{array}{l}.1478 \\
.1506\end{array}$ & $\begin{array}{l}.1514 \\
.1514\end{array}$ \\
\hline $2^{1} \mathrm{~S} \rightarrow 4^{1} \mathrm{P}$ & .11490 & $\begin{array}{l}\text { len. } \\
\text { vel. }\end{array}$ & .051 & $\begin{array}{l}.0513 \\
.0498\end{array}$ & $\begin{array}{l}.0493 \\
.0506\end{array}$ & $\begin{array}{l}.0508 \\
.0506\end{array}$ & \\
\hline $3^{1} \mathrm{~S} \rightarrow 2^{1} \mathrm{P}$ & 0.06257 & len. & & & $\begin{array}{r}0.1458 \\
1446\end{array}$ & $\begin{array}{r}0.1425 \\
1462\end{array}$ & \\
\hline $3^{1} \mathrm{~S} \rightarrow 3^{1} \mathrm{P}$ & .00612 & $\begin{array}{l}\text { len. } \\
\text { vel. }\end{array}$ & & & $\begin{array}{l}.6280 \\
.645\end{array}$ & $\begin{array}{l}.625 \\
.634\end{array}$ & \\
\hline $3^{1} \mathrm{~S} \rightarrow 4^{1} \mathrm{P}$ & .03020 & $\begin{array}{l}\text { len. } \\
\text { vel. }\end{array}$ & & & $\begin{array}{l}.1429 \\
.1433\end{array}$ & $\begin{array}{l}.134 \\
.145\end{array}$ & \\
\hline $2^{1} \mathrm{P} \rightarrow 3^{1} \mathrm{D}$ & 0.06822 & $\begin{array}{l}\text { len. } \\
\text { vel. }\end{array}$ & 0.738 & $\begin{array}{r}0.738 \\
.711\end{array}$ & $\begin{array}{r}0.7106 \\
.7095\end{array}$ & $\begin{array}{r}0.7064 \\
.7148\end{array}$ & \\
\hline $3^{1} \mathrm{P} \rightarrow 3^{1} \mathrm{D}$ & .00048 & $\begin{array}{l}\text { len. } \\
\text { vel. }\end{array}$ & .021 & $\begin{array}{l}.021 \\
.064\end{array}$ & $\begin{array}{l}.022 \\
.021\end{array}$ & $\begin{array}{l}.021 \\
026\end{array}$ & \\
\hline $4^{1} \mathrm{P} \rightarrow 3^{1} \mathrm{D}$ & .02454 & $\begin{array}{l}\text { len. } \\
\text { vel. }\end{array}$ & & & $\begin{array}{l}.0152 \\
.0152\end{array}$ & $\begin{array}{l}.0142 \\
.0144\end{array}$ & \\
\hline
\end{tabular}

a See reference [12].

${ }^{\mathrm{b}}$ See reference [13].

${ }^{c}$ See reference [5].

d See reference [4].

TABLE 3. Comparison of oscillator strength calculations for neutral heliumthe triplet transitions

\begin{tabular}{|c|c|c|c|c|c|c|c|}
\hline Transition & $\Delta E$ (а.u.) & Type & $\begin{array}{c}\text { Cou- } \\
\text { lomb } \\
\text { approx. }^{\text {a }}\end{array}$ & $\begin{array}{c}\text { Hartree } \\
\text { Fock }^{b}\end{array}$ & $\begin{array}{c}\text { Config- } \\
\text { uration } \\
\text { inter- } \\
\text { action }^{c}\end{array}$ & $\begin{array}{l}\text { This } \\
\text { paper }\end{array}$ & $\begin{array}{l}\text { Accu- } \\
\text { rate }^{d}\end{array}$ \\
\hline $2^{3} \mathrm{~S} \rightarrow 2^{3} \mathrm{P}$ & 0.04207 & $\begin{array}{l}\text { len. } \\
\text { vel. }\end{array}$ & 0.538 & $\begin{array}{r}0.558 \\
611\end{array}$ & $\begin{array}{r}0.5398 \\
5487\end{array}$ & $\begin{array}{r}0.5391 \\
5401\end{array}$ & $\begin{array}{r}0.5391 \\
5391\end{array}$ \\
\hline $2^{3} \mathrm{~S} \rightarrow 3^{3} \mathrm{P}$ & .11715 & len. & .063 & $\begin{array}{l}.0569 \\
.0503\end{array}$ & .0644 & .0641 & .0645 \\
\hline $2^{3} \mathrm{~S} \rightarrow 4^{3} \mathrm{P}$ & .14288 & $\begin{array}{l}\text { len. } \\
\text { vel. }\end{array}$ & .026 & $\begin{array}{r}.0234 \\
.0204\end{array}$ & $\begin{array}{l}.0259 \\
0271\end{array}$ & $\begin{array}{r}.0240 \\
0222\end{array}$ & \\
\hline $3^{3} \mathrm{~S} \rightarrow 2^{3} \mathrm{P}$ & .06446 & $\begin{array}{l}\text { len. } \\
\text { vel. }\end{array}$ & & & $\begin{array}{l}.209 \\
.206\end{array}$ & $\begin{array}{l}.207 \\
.209\end{array}$ & \\
\hline $3^{3} \mathrm{~S} \rightarrow 3^{3} \mathrm{P}$ & .01061 & $\begin{array}{l}\text { len. } \\
\text { vel. }\end{array}$ & & & $\begin{array}{l}.892 \\
.911\end{array}$ & $\begin{array}{l}.891 \\
.898\end{array}$ & \\
\hline $3^{3} \mathrm{~S} \rightarrow 4^{3} \mathrm{P}$ & .03637 & $\begin{array}{l}\text { len. } \\
\text { vel. }\end{array}$ & & & $\begin{array}{l}.0499 \\
.0491\end{array}$ & $\begin{array}{l}.0433 \\
.0425\end{array}$ & \\
\hline $2^{3} \mathrm{P} \rightarrow 3^{3} \mathrm{D}$ & .07753 & $\begin{array}{l}\text { len. } \\
\text { vel. }\end{array}$ & .620 & $\begin{array}{l}.637 \\
.610\end{array}$ & $\begin{array}{l}.6105 \\
.6269\end{array}$ & $\begin{array}{l}.6084 \\
.6121\end{array}$ & \\
\hline $3^{3} \mathrm{P} \rightarrow 3^{3} \mathrm{D}$ & .00245 & len. & .112 & .112 & .1130 & .1121 & \\
\hline $4^{3} \mathrm{P} \rightarrow 3^{3} \mathrm{D}$ & .02329 & $\begin{array}{l}\text { vel. } \\
\text { len. } \\
\text { vel. }\end{array}$ & & .074 & $\begin{array}{l}.1216 \\
.0372 \\
.0378\end{array}$ & $\begin{array}{l}.1097 \\
.0340 \\
.0344\end{array}$ & \\
\hline
\end{tabular}

\footnotetext{
a See reference [12].

${ }^{\mathrm{b}}$ See reference [13].

c See reference [5].

d See reference [4].
}

played here are good. A straight average of the presumably most sophisticated calculations (both length and velocity) of the last three columns provides a value with which any one of these individual calculations agrees to within 5 to 10 percent, and often much better.
Even the Coulomb approximation agrees very well with such a "recommended" value. It is obvious that the helium spectrum is quite Coulombic with the transitions corresponding either to a lone electron jumping around outside a very compact core, or to a single electron jumping out of a very compact ground state to a very diffuse orbital. Clearly, calculations of the degree of sophistication of the $r_{12}$ or configuration interaction approximations amount to using an elephant gun to kill a gnat.

However, the elephant gun will continue to be used for the rest of the isoelectronic sequence. One reason for doing so is the fact that the energy level data needed for the Coulomb approximation rapidly becomes quite sparse along the sequence. Variational calculations such as the present ones generate their own energy levels and, as a byproduct, make some term value predictions of some interest in their own right. Secondly, and most importantly, the degree of "overkill" attained by such calculations, as indicated by neutral $\mathrm{He}$, provides a valuable accuracy cushion for the prediction of these unknown oscillator strengths.

The total energies computed for the isoelectronic sequence through $\mathrm{Ne}^{+8}$ are shown in table 4 . A comparison with some more accurate values for $\mathrm{Li}^{+}[7,8,9]$, indicates agreement in the total energy always within $1 \times 10^{-5}$ a.u. The ground state energies agree better than this with the calculations of Pekeris [7] for the entire sequence. Probably the most interesting feature of these calculations is the prediction that the $2^{1} \mathrm{~S}$ and $2^{3} \mathrm{P}$ levels interchange their positions as one moves along the isoelectronic sequence, with the crossing taking place between $\mathrm{C}^{+4}$ and $\mathrm{N}^{+5}$. It can also be seen that the $3^{1} \mathrm{P}$ level remains the highest of the $n=3$ levels for the entire sequence, at least through $\mathrm{Ne}^{+8}$. It is well-known for neutral helium that, among all the levels arising from the same principal quantum numbers, e.g., $4^{1,3} \mathrm{~S}, 4^{1,3} \mathrm{P}, \ldots$. . the ${ }^{1} \mathrm{P}$ is always the highest, at least through $n=7$. These results suggest that this remains the case for the isoelectronic positive ions, certainly for $n=3$.

It should be emphasized that all of these calculations are purely nonrelativistic and, hence, include none of the shift or splitting due to relativistic or radiative corrections. While these nonrelativistic values are probably quite accurate, such corrections can become large for the higher ions. The point of the present calculations has been to obtain wavefunctions with which to compute the oscillator strengths and not to accurately predict observable energies. Also, although the energy corrections are large, the nonrelativistic calculations still give a fairly detailed and accurate representation of the spectrum. This is illustrated by table 5 , where the calculated and observed [3] term values of $\mathrm{O}$ VII are compared. The relativistic and Lamb shifts in the ground state have been calculated [7] to be $3550 \mathrm{~cm}^{-1}$ and $-380 \mathrm{~cm}^{-1}$, respectively, which compares well with the error here of $3020 \mathrm{~cm}^{-1}$. The experimental ground state term value is uncertain by $600 \mathrm{~cm}^{-1}$. For $\mathrm{Li}^{+}$, the relativistic shifts in the $1^{1} \mathrm{~S}, 2^{1} \mathrm{~S}, 2^{3} \mathrm{~S}, 2^{1} \mathrm{P}$ levels have been calculated [9] as $19.7,6.5,16.9,5.6 \mathrm{~cm}^{-1}$ respec- 
TABLE 4. Computed total energies, - E, (in a.u.) for the helium isoelectronic sequence

\begin{tabular}{|c|c|c|c|c|c|c|c|c|c|c|}
\hline Term & & 2 & 3 & 4 & 5 & 6 & 7 & 8 & 9 & 10 \\
\hline $1^{1} \mathrm{~S}$ & 53 & 2.90372 & 7.27991 & 13.65557 & 22.03097 & 32.40624 & 44.78144 & 59.15660 & 75.53171 & 93.90680 \\
\hline $2^{3} \mathrm{~S}$ & 54 & 2.17523 & 5.11073 & 9.29717 & 14.73390 & 21.42076 & 29.35768 & 38.54464 & 48.98164 & 60.66865 \\
\hline $2^{1} \mathrm{~S}$ & 54 & 2.14597 & 5.04087 & 9.18487 & 14.57852 & 21.22198 & 29.11540 & 38.25875 & 48.65204 & 60.29530 \\
\hline $2^{3} \mathrm{P}$ & 52 & 2.13316 & 5.02771 & 9.17497 & 14.57313 & 21.22171 & 29.12050 & 38.26942 & 48.66842 & 60.31748 \\
\hline $2^{1} \mathrm{P}$ & 52 & 2.12384 & 4.99335 & 9.11077 & 14.47728 & 21.09333 & 28.95911 & 38.07473 & 48.44024 & 60.05567 \\
\hline $3^{3} \mathrm{P}$ & 52 & 2.05806 & 4.73045 & 8.51460 & 13.41003 & 19.41672 & 26.53455 & 34.76352 & 44.10361 & 54.55484 \\
\hline $3^{3} \mathrm{D}$ & 52 & 2.05564 & 4.72253 & 8.50058 & 13.38977 & 19.39008 & 26.50151 & 34.72405 & 44.05771 & 54.50248 \\
\hline $3^{1} \mathrm{D}$ & 52 & 2.05562 & 4.72237 & .8 .50020 & 13.38906 & 19.38901 & 26.50006 & 34.72218 & 44.05542 & 54.49974 \\
\hline $3^{1} \mathrm{P}$ & 52 & 2.05513 & 4.72018 & 8.49594 & 13.38268 & 19.38049 & 26.48943 & 34.70935 & 44.04044 & 54.48266 \\
\hline
\end{tabular}

TABLE 5. Computed and observed term values relative to the ionization limit $\left(\right.$ in $\left.\mathrm{cm}^{-1}\right)$ for $\mathrm{O}$ VII

\begin{tabular}{r|r|r|r}
\hline \hline Term & Computed & Observed a $^{\text {a }}$ & Error \\
\hline & & & \\
$1^{1} \mathrm{~S}$ & 5959980 & 5963000 & 3020 \\
$2^{3} \mathrm{~S}$ & 1436330 & 1437730 & 1400 \\
$2^{3} \mathrm{P}_{2 .}$ & 1375930 & 1376140 & 460 (ave.) \\
${ }^{3} \mathrm{P}_{1}$, & & 690 & \\
${ }^{3} \mathrm{P}_{0}$ & & 750 & \\
$2^{1} \mathrm{~S}$ & 1373590 & - & \\
$2^{1} \mathrm{P}$ & 1333200 & 1333800 & 600 \\
$3^{3} \mathrm{P}$ & 606500 & 606700 & 200 \\
$3^{3} \mathrm{D}$ & 597840 & 597930 & 90 \\
$3^{1} \mathrm{D}$ & 597430 & - & \\
$3^{1} \mathrm{P}$ & 594610 & 594450 & 160 \\
\hline
\end{tabular}

a See reference [3].

tively, so the excited state errors here are, at least, not unreasonable. The unobserved $2^{1} \mathrm{~S}$ level is here predicted to lie about $1600 \mathrm{~cm}^{-1}$ above the $2^{3} \mathrm{P}$ center of gravity.

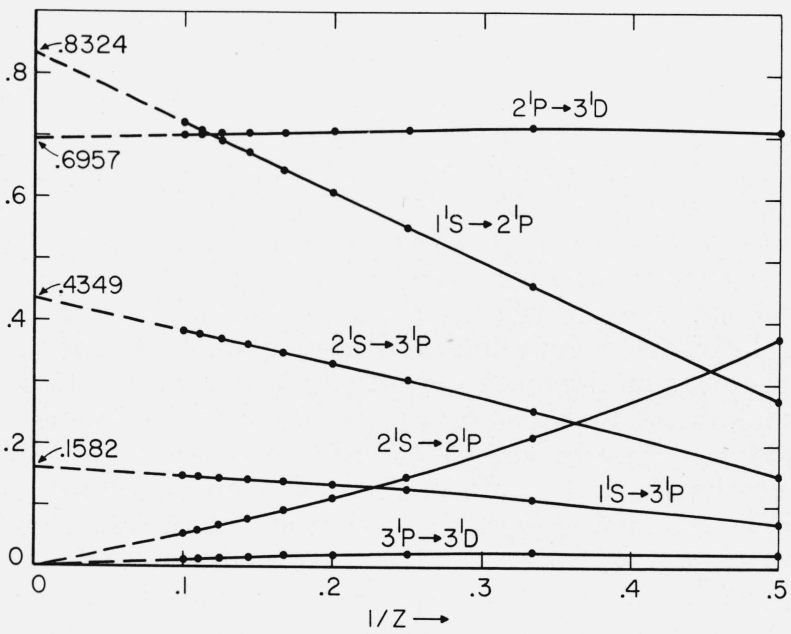

FIGURE 1. Singlet oscillator strengths for the helium isoelectronic sequence versus $1 / \mathrm{Z}$.
The oscillator strengths, finally, are given in tables 6 and 7 , and they are plotted as a function of $1 / Z$ in figures 1 and 2. As has been pointed out earlier [14], the oscillator strength for an isoelectronic sequence has a descending power of $Z$ expansion of the form

$$
f=a_{0}+a_{1} / Z+a_{2} / Z^{2}+\ldots .
$$

where $a_{0}$ is just the oscillator strength computed in a purely hydrogenic approximation (if there are no zeroth order degeneracies). Also, $a_{0}$ vanishes for transitions involving no change in the principal quantum number. Thus, the infinite $Z$ limit is either the hydrogenic value or zero, depending on whether $n \rightarrow n^{\prime}$ or $n \rightarrow n$, and it can be seen that all the plotted $f$-values (mean of length and velocity) behave very nicely in accordance with these limiting situations.

\section{Conclusions}

In general, it seems reasonable to recommend the mean of the length and velocity values for any given transition of the sequence with an uncertainty of about

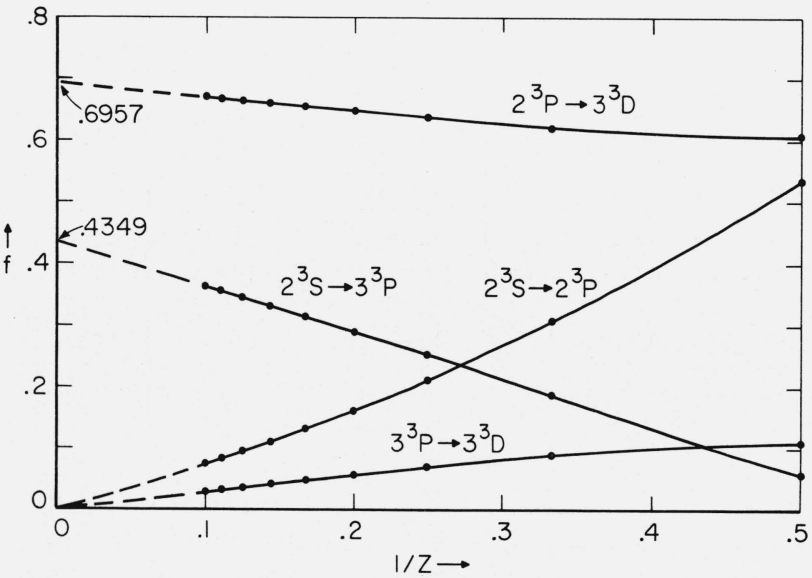

FIGURE 2. Triplet oscillator strengths for the helium isoelectronic sequence versus $1 / \mathrm{Z}$. 
TABLE 6. Oscillator strengths for the helium isoelectronic sequence-singlet transitions

\begin{tabular}{|c|c|c|c|c|c|c|c|c|c|c|}
\hline Transition & $Z$ & 2 & 3 & 4 & 5 & 6 & 7 & 8 & 9 & 10 \\
\hline \multirow{2}{*}{$1^{1} \mathrm{~S} \rightarrow 2^{1} \mathrm{P}$} & $v$. & $\begin{array}{r}0.2761 \\
.2759\end{array}$ & $\begin{array}{r}0.4566 \\
.4565\end{array}$ & $\begin{array}{r}0.5515 \\
.5515\end{array}$ & $\begin{array}{r}0.6089 \\
.6089\end{array}$ & $\begin{array}{r}0.6470 \\
.6470\end{array}$ & $\begin{array}{r}0.6742 \\
.6742\end{array}$ & $\begin{array}{r}0.6944 \\
.6944\end{array}$ & $\begin{array}{r}0.7101 \\
.7101\end{array}$ & $\begin{array}{r}0.7226 \\
.7226\end{array}$ \\
\hline & $\Delta E$ & 0.77988 & 2.28657 & 4.54480 & 7.55369 & 11.31291 & 15.82233 & 21.08187 & 27.09147 & 33.85113 \\
\hline \multirow{2}{*}{${ }^{1} \mathrm{~S} \rightarrow 3^{1} \mathrm{P}$} & $v$. & $\begin{array}{l}.0730 \\
.0734\end{array}$ & $\begin{array}{r}0.1103 \\
.1107\end{array}$ & $\begin{array}{r}0.1267 \\
.1269\end{array}$ & $\begin{array}{r}0.1352 \\
.1355\end{array}$ & $\begin{array}{r}0.1404 \\
.1406\end{array}$ & $\begin{array}{r}0.1438 \\
.1439\end{array}$ & $\begin{array}{r}0.1461 \\
.1462\end{array}$ & $\begin{array}{r}0.1478 \\
.1479\end{array}$ & $\begin{array}{r}0.1492 \\
.1492\end{array}$ \\
\hline & $\Delta E$ & 0.84859 & 2.55973 & 5.15963 & 8.64829 & 13.02575 & 18.29201 & 24.44725 & 31.49127 & 39.42414 \\
\hline \multirow{2}{*}{$2^{1} \mathrm{~S} \rightarrow 2^{1} \mathrm{P}$} & $v$. & $\begin{array}{l}.3774 \\
.3764\end{array}$ & $\begin{array}{r}0.2129 \\
.2126\end{array}$ & $\begin{array}{r}0.1487 \\
.1485\end{array}$ & $\begin{array}{r}0.1145 \\
.1144\end{array}$ & $\begin{array}{r}0.0932 \\
.0930\end{array}$ & $\begin{array}{r}0.0786 \\
.0785\end{array}$ & $\begin{array}{r}0.0679 \\
.0679\end{array}$ & $\begin{array}{r}0.0599 \\
.0598\end{array}$ & $\begin{array}{r}0.0535 \\
.0534\end{array}$ \\
\hline & $\Delta E$ & 0.02213 & 0.04753 & 0.07410 & 0.10124 & 0.12865 & 0.15629 & 0.18402 & 0.21180 & 0.23963 \\
\hline \multirow{2}{*}{$2^{1} \mathrm{~S} \rightarrow 3^{1} \mathrm{P}$} & $v$. & $\begin{array}{l}.1506 \\
.1478\end{array}$ & $\begin{array}{l}.2568 \\
.2551\end{array}$ & $\begin{array}{l}.3061 \\
.3046\end{array}$ & $\begin{array}{l}.3340 \\
.3326\end{array}$ & $\begin{array}{l}.3524 \\
.3495\end{array}$ & $\begin{array}{l}.3647 \\
.3627\end{array}$ & $\begin{array}{l}.3736 \\
.3728\end{array}$ & $\begin{array}{l}.3807 \\
.3791\end{array}$ & $\begin{array}{l}.3869 \\
.3841\end{array}$ \\
\hline & $\Delta E$ & 0.09083 & 0.32069 & 0.68892 & 1.19584 & 1.84149 & 2.62597 & 3.54940 & 4.61160 & 5.81264 \\
\hline \multirow{2}{*}{$2^{1} \mathrm{P} \rightarrow 3^{1} \mathrm{D}$} & $v$. & $\begin{array}{l}.7148 \\
.7064\end{array}$ & $\begin{array}{l}.7173 \\
.7108\end{array}$ & $\begin{array}{l}.7139 \\
.7084\end{array}$ & $\begin{array}{r}0.7121 \\
.7065\end{array}$ & $\begin{array}{r}0.7096 \\
.7046\end{array}$ & $\begin{array}{r}0.7078 \\
.7034\end{array}$ & $\begin{array}{r}0.7065 \\
.7024\end{array}$ & $\begin{array}{r}0.7050 \\
.7016\end{array}$ & $\begin{array}{r}0.7042 \\
.7009\end{array}$ \\
\hline & $\Delta E$ & 0.06822 & 0.27097 & 0.61057 & 1.08822 & 1.70432 & 2.45906 & 3.35254 & 4.38482 & 5.55593 \\
\hline \multirow{2}{*}{$3^{1} \mathrm{P} \rightarrow 3^{1} \mathrm{D}$} & $v$. & $\begin{array}{l}.0249 \\
.0212\end{array}$ & $\begin{array}{l}.0288 \\
.0244\end{array}$ & $\begin{array}{l}.0242 \\
.0211\end{array}$ & $\begin{array}{r}0.0221 \\
.0178\end{array}$ & $\begin{array}{r}0.0188 \\
.0152\end{array}$ & $\begin{array}{r}0.0165 \\
.0132\end{array}$ & $\begin{array}{r}0.0147 \\
.0117\end{array}$ & $\begin{array}{r}0.0131 \\
.0105\end{array}$ & $\begin{array}{r}0.0118 \\
.0095\end{array}$ \\
\hline & $\Delta E$ & 0.00048 & 0.00219 & 0.00426 & 0.00638 & 0.00852 & 0.01063 & 0.01283 & 0.01498 & 0.01708 \\
\hline
\end{tabular}

5 percent. The length-velocity agreement is usually much better than this, and the experience with helium indicates that it should be a safe margin of uncertainty. The sole exception is the $3^{1} \mathrm{P}-3^{1} \mathrm{D}$ transition, where the length-velocity disagreement is somewhat larger, and this transition should probably be regarded with some skepticism for the entire sequence, although the length value is probably to be preferred. The energy differences here are small, indicating a very small velocity transition moment, which is thus apt to be unreliable, as suggested by the comparisons of table 2 . For the higher members of the sequence, the oscillator strengths, at least the non-relativistic values, can be read directly off the curves of figures 1 and 2 .

For very highly ionized species, intersystem transitions become strong and eventually will begin to steal oscillator strength from the allowed transitions. This probably does not become too serious for the ions computed here. The spin interactions are still rather weak compared to the electrostatic, e.g., the ${ }^{3} \mathrm{P}$ spin splitting in $\mathrm{O}$ VII is about $600 \mathrm{~cm}^{-1}$ while the ${ }^{3 \mathrm{P}-1} \mathrm{P}$ separation is of the order of $40,000 \mathrm{~cm}^{-1}$. However, the precise effect of the intersystem transitions will have to await further calculations. 
TABLE 7. Oscillator strengihs for the helium isoelectronic sequence-triplet transitions

\begin{tabular}{|c|c|c|c|c|c|c|c|c|c|c|}
\hline \multirow{2}{*}{$2^{3} \mathrm{~S} \rightarrow 2^{3} \mathrm{P}$} & $\begin{array}{l}v . \\
l .\end{array}$ & $\begin{array}{r}0.5401 \\
.5391\end{array}$ & $\begin{array}{r}0.3086 \\
.3080\end{array}$ & $\begin{array}{r}0.2135 \\
.2131\end{array}$ & $\begin{array}{r}0.1627 \\
.1626\end{array}$ & $\begin{array}{r}0.1315 \\
.1314\end{array}$ & $\begin{array}{r}0.1102 \\
.1102\end{array}$ & $\begin{array}{r}0.0949 \\
.0948\end{array}$ & $\begin{array}{r}0.0832 \\
.0833\end{array}$ & $\begin{array}{r}0.0742 \\
.0742\end{array}$ \\
\hline & $\Delta E$ & 0.04207 & 0.08301 & 0.12220 & 0.16077 & 0.19905 & 0.23718 & 0.27522 & 0.31322 & 0.35117 \\
\hline \multirow{2}{*}{$2^{3} \mathrm{~S} \rightarrow 3^{3} \mathrm{P}$} & $v$. & $\begin{array}{l}.0634 \\
.0641\end{array}$ & $\begin{array}{l}.1857 \\
.1872\end{array}$ & $\begin{array}{l}.2523 \\
.2526\end{array}$ & $\begin{array}{l}.2908 \\
.2910\end{array}$ & $\begin{array}{l}.3163 \\
.3163\end{array}$ & $\begin{array}{l}.3343 \\
.3341\end{array}$ & $\begin{array}{l}.3476 \\
.3470\end{array}$ & $\begin{array}{l}.3576 \\
.3572\end{array}$ & $\begin{array}{l}.3656 \\
.3651\end{array}$ \\
\hline & $\Delta E$ & 0.11717 & 0.38028 & 0.78157 & 1.32387 & 2.00404 & 2.82313 & 3.78112 & 4.87803 & 6.11381 \\
\hline \multirow{2}{*}{$2^{3} \mathrm{P} \rightarrow 3^{3} \mathrm{D}$} & $v$. & $\begin{array}{l}.6121 \\
.6084\end{array}$ & $\begin{array}{l}.6263 \\
.6243\end{array}$ & $\begin{array}{l}.6404 \\
.6390\end{array}$ & $\begin{array}{l}.6504 \\
.6493\end{array}$ & $\begin{array}{l}.6575 \\
.6565\end{array}$ & $\begin{array}{l}.6626 \\
.6618\end{array}$ & $\begin{array}{l}.6667 \\
.6659\end{array}$ & $\begin{array}{l}.6696 \\
.6691\end{array}$ & $\begin{array}{r}0.6723 \\
.6717\end{array}$ \\
\hline & $\Delta E$ & 0.07753 & 0.30519 & 0.67439 & 1.18336 & 1.83163 & 2.61899 & 3.54537 & 4.61071 & 5.81500 \\
\hline \multirow{2}{*}{$3^{3} \mathrm{P} \rightarrow 3^{3} \mathrm{D}$} & $v$. & $\begin{array}{l}.1097 \\
.1121\end{array}$ & $\begin{array}{l}.0901 \\
.0906\end{array}$ & $\begin{array}{l}.0712 \\
.0711\end{array}$ & $\begin{array}{l}.0578 \\
.0577\end{array}$ & $\begin{array}{l}.0485 \\
.0485\end{array}$ & $\begin{array}{l}.0420 \\
.0417\end{array}$ & $\begin{array}{l}.0368 \\
.0365\end{array}$ & $\begin{array}{l}.0328 \\
.0325\end{array}$ & $\begin{array}{l}.0294 \\
.0293\end{array}$ \\
\hline & $\Delta E$ & .00243 & .00792 & .01402 & .02026 & .02664 & .03304 & .03947 & .04590 & .05236 \\
\hline
\end{tabular}

\section{References}

[1] G. Herzberg and H. R. Moore, Can. J. Phys. 37, 1293 (1959).

[2] W. C. Martin, J. Res. NBS 64A, 19 (1960).

[3] B. Edlen, Arkiv f. Fysik 4, 441 (1951).

[4] B. Schiff and C. L. Pekeris, Phys. Rev. 134, A638 (1964).

[5] L. C. Green, N. C. Johnson and E. K. Kolchin, Astrophys. J. 144,369 (1966).

[6] E. A. Hylleraas, Z. Physik 54, 347 (1929).

[7] C. L. Pekeris, Phys. Rev. 112,1649 (1958); Phys. Rev. 115 , 1216 (1959).

[8] C. L. Pekeris, Phys. Rev. 127, 509 (1962); C. L. Pekeris, B. Schiff, and H. Lifson, Phys. Rev. 126, 1057 (1962).
[9] C. L. Pekeris, Phys. Rev. 126, 143 (1962); B. Schiff, H. Lifson, C. L. Pekeris, and P. Rabinowitz, Phys. Rev. 140, A1104, (1965).

[10] L. C. Green, E. K. Kolchin, and N. C. Johnson, Phys. Rev. 139, A373 (1965).

[11] J. K. L. MacDonald, Phys. Rev. 43, 830 (1933).

[12] D. R. Bates and A. Damgaard, Phil. Trans. Roy. Soc. A242, 101 (1949).

[13] E. Trefftz, A. Schlüter, K. Dettmar, and K. Jörgens, Z. Astrophys. 44, 1 (1957).

[14] A. W. Weiss, Astrophys. J. 138, 1262 (1963).

(Paper 71A2-448) 